\title{
A method for preparation of a high-quality high temperature superconducting ceramics
}

\author{
L A KOTOK, L A KVICHKO, V T ZAGOSKIN, \\ Yu G LITVINENKO and E T MOGHILKO \\ Institute for Single Crystals, Lenin av.60, Kharkov 310141, USSR
}

\begin{abstract}
An improved method for hot pressing of high temperature superconducting (HTSC) powders prepared by conventional solid phase synthesis of the initial $\mathrm{BaCO}_{3}, \mathrm{CuO}$ and $\mathrm{Ln}_{2} \mathrm{O}_{3}$ allows one to obtain HTSC targets and magnetic shields possessing a high degree of homogeneity. By sputtering such targets HTSC films with critical current density of $3.3 \cdot 10^{\circ} \mathrm{A} / \mathrm{cm}^{2}$ have been deposited. Shields, prepared according to this method, show a shielding coefficient of $10^{5}$ and $H_{c}$ of 79 Öe in the constant magnetic field and in the alternating magnetic field the amplitude is $900 \mathrm{O}$ in the frequency range of $70-3000 \mathrm{~Hz}$.
\end{abstract}

Keywords. Hot pressing; high temperature superconducting ceramics; magnetic shields; solid phase synthesis.

\section{Introduction}

In an attempt to work out a method for preparation of HTSC ceramics the physicochemical regularities of the formation process, the region of temperature stability and the decomposition kinetics of the superconducting phase in the compounds of the composition $\mathrm{LnBa}_{2} \mathrm{Cu}_{3} \mathrm{O}_{7 y}$, where $\mathrm{Ln}=\mathrm{La}, \mathrm{Y}, \mathrm{Sm}, \mathrm{Eu}, \mathrm{Gd}$. Dy, Er, Tm, Ho, Yb have been studied. Differential thermal analysis (DTA), thermogravimetry (TG), X-ray diffraction analysis including high temperature, dilatometry, electron microscopy and electron-probe microanalysis have been used for this study.

Determination of regularities of phase formation has made it possible to optimize conditions for the synthesis and develop a method for preparation of HTSC materials with a reproducible complex of the set properties by a ceramic technique using raw materials with various prehistories.

\section{Results and discussion}

The scaled-up production technique for materials with preset properties is based on a well-known procedure of solid-phase interaction of $\mathrm{BaCO}_{3}, \mathrm{CuO}$ and $\mathrm{Ln}_{2} \mathrm{O}_{3}$ initial compounds during heat treatment. The electrophysical properties of HTSC compounds strongly depend on their phase composition defined by synthesis conditions. We have studied the dependence of superconducting properties on the phase composition, oxygen partial pressure and synthesis temperatures of $\mathrm{LnBa}_{2} \mathrm{Cu}_{3} \mathrm{O}_{7-y^{-}}$ type compounds (where $\mathrm{Ln}=\mathrm{La}, \mathrm{Y}, \mathrm{Sm}, \mathrm{Eu}, \mathrm{Gd}, \mathrm{Dy}, \mathrm{Er}, \mathrm{Tm}, \mathrm{Ho}, \mathrm{Yb}$ ).

By means of thermogravimetry, dilatometry, $X$-ray diffraction and electron-probe microanalysis it has been established that the 1 2-3 superconducting phase formed via the intermediate compounds $\mathrm{Ln}_{2} \mathrm{BaCuO}_{5}$ (I) and $\mathrm{BaCuO}_{2}$ (II) is stable in a narrow $T_{\text {form }}-T_{\text {decomp }}$ temperature interval and is decomposed into the same compounds $I$, $\mathrm{II}$ and $\mathrm{CuO}$ (III).

The values of $T_{0}$ (i.e. the temperature of $1-2-3$ compound formation) for various 
rare-earth elements are in the range of $840-980^{\circ} \mathrm{C}$. The values of decomposition temperature ( $\left.T_{\text {decomp }}\right)$ increase with increase of rare-earth element radius and oxygen partial pressure (Seminozhenko et al 1988; Blank et al 1988). The duration of the initial material heat treatment in the process of synthesis is limited by the interaction rate of barium carbonate with copper oxides and rare-earth elements at a preset temperature.

To optimize the use of powders required for preparation of ceramics, the kinetics of 1-2-3 phase formation has been investigated by means of heat treatment of $\mathrm{Y}_{2} \mathrm{O}_{3}$, $\mathrm{CuO}$ and $\mathrm{BaCO}_{3}$ stoichiometric compound.

The interaction degree of the components has been determined with respect to the residual carbonate ion content in the samples which have undergone isothermal treatment of varying durations. The kinetics of the process calculated with respect to the interaction degree is in good agreement with the results of 1-2-3 phase content determination using $\mathrm{X}$-ray phase analysis.

At various stages of the synthesis pressed powder samples have been made, their phase composition and $T_{c}$ being determined. The best quality samples have been obtained when the 1-2-3 phase content is not less than $95 \%$ (figure 1 ). The production technique consists of preparation of the initial components, their mixing in stoichiometric ratio and heat treatment with a gradual temperature rising up to $T_{0}$. Heating is repeated several times, the tablets being ground and homogenized before every heating. The residue mainly consists of particles up to 5-6 $\mu \mathrm{m}$.

It has been found (Antonova et al 1988) that the two-stage process of ceramic sample preparation including pressing at room temperature and subsequent heating prevents essential densification of HTSC ceramics. However, simultaneous pressure and heating effects provide a considerable increase of density and promote the preparation process.

Synthesized HTSC powder is briquetted in dies made of $\mathrm{Cr}-\mathrm{Ni}$ alloy and pressed at a temperature of $600-900^{\circ} \mathrm{C}$ and a pressure up to $0.6 \mathrm{GPa}$ to obtain ceramics.

Heating, cooling, pressure loading and unloading rates are chosen by experiments

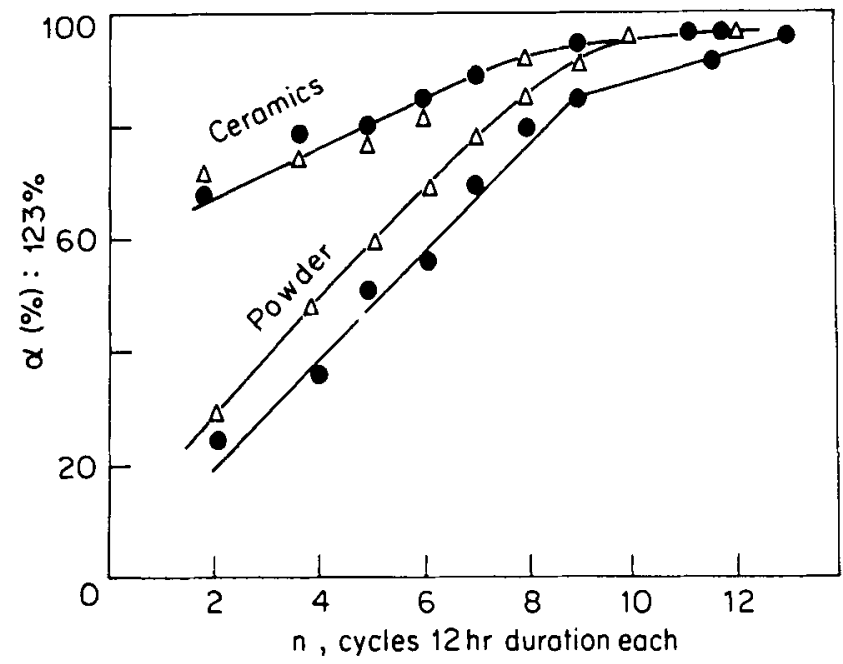

Figure 1. 1-2-3 phase content $(\Delta)$ and transformation degree $(\Theta)$ in powder and tablets vs heat treatment time. 
to prevent the samples from heat cracking and to provide the complete transition of 1-2-3 tetragonal phase into orthorhombic modification (Zagoskin et al 1988).

By pressure and hot-pressing temperature variations the ceramic density may be modified over a wide range, as shown in figure 2 . Special attention should be paid to the homogeneity of temperature distribution over the samples, since the tablet density is inhomogeneous along the sample diameter owing to the temperature gradient on the plane perpendicular to compressing pressure. This inhomogeneity may be eliminated by choosing proper heating conditions for the die and proper arrangement for heating. The reduction of the temperature difference between the tablet centre and its side surface favours preparation of density-uniform ceramics (figure 3).

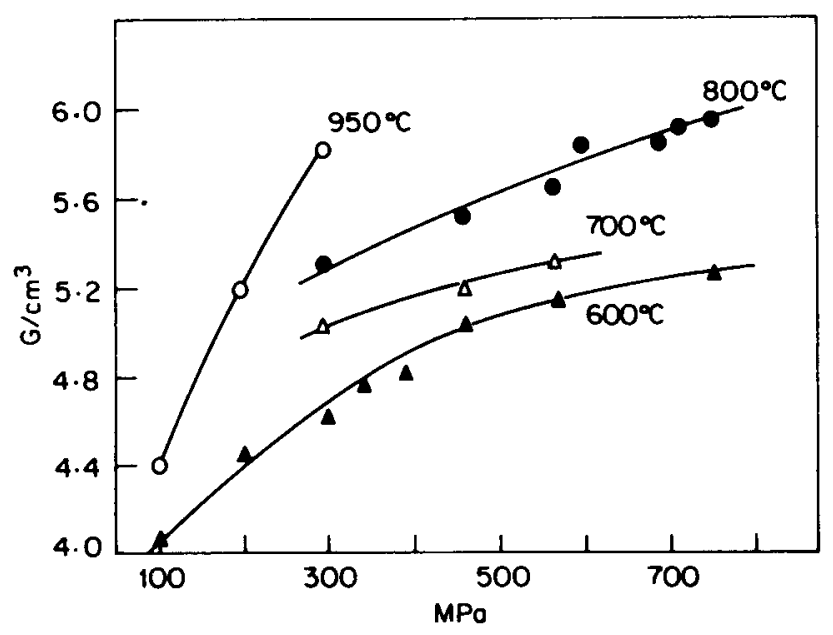

Figure 2. $\mathrm{YBa}_{2} \mathrm{Cu}_{3} \mathrm{O}_{1-y}$ ceramics density dependence vs pressure and temperature of hot pressing.

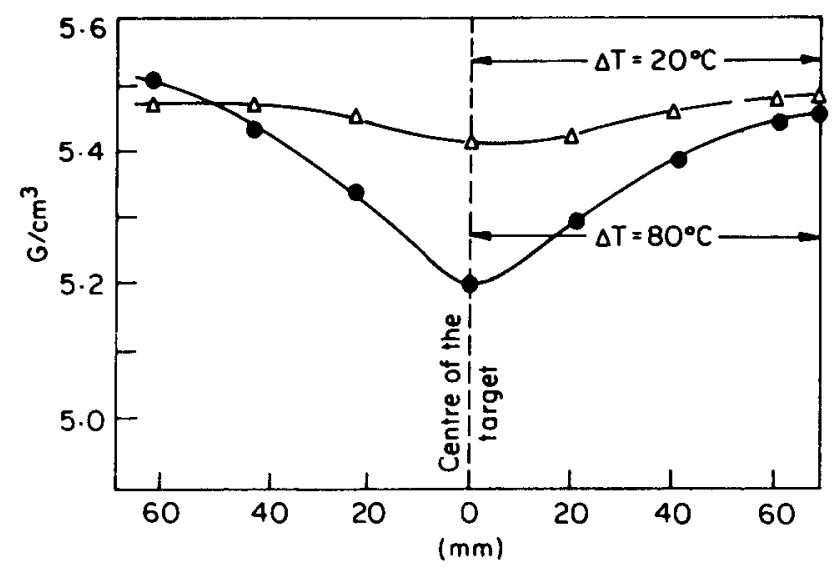

Figure 3. Radial distribution of the material density of the ceramic HTSC target $\mathrm{YBa}_{2} \mathrm{Cu}_{3} \mathrm{O}_{7-\jmath}$, dia $68 \mathrm{~mm}$. (a) $\Delta T=80^{\circ} \mathrm{C}$, (b) $\Delta T=20^{\prime} \mathrm{C}$. 


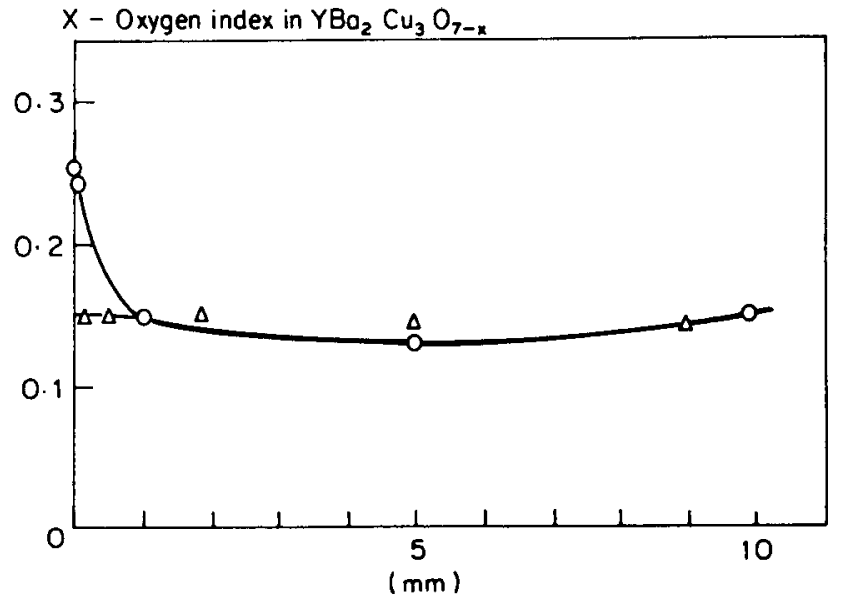

Figure 4. Oxygen content (index $x$ ) in the material of the $\mathrm{YBa}_{2} \mathrm{Cu}_{3} \mathrm{O}_{7-}$, target at various distances from its surface. ( ) before heating. ( $\triangle$ ) after additional heating.

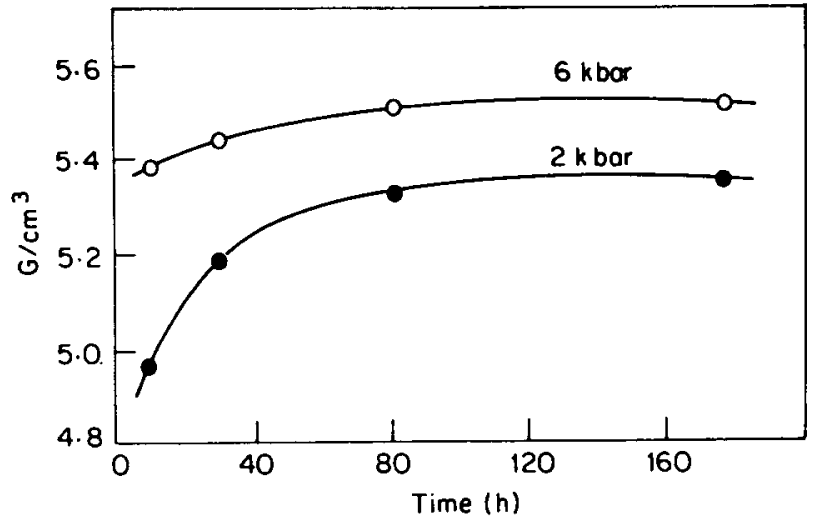

Figure 5. $\mathrm{YBa}_{2} \mathrm{Cu}_{3} \mathrm{O}_{7-\ldots}$, ceramics density vs pressure of hot pressing and the time of additional heating.

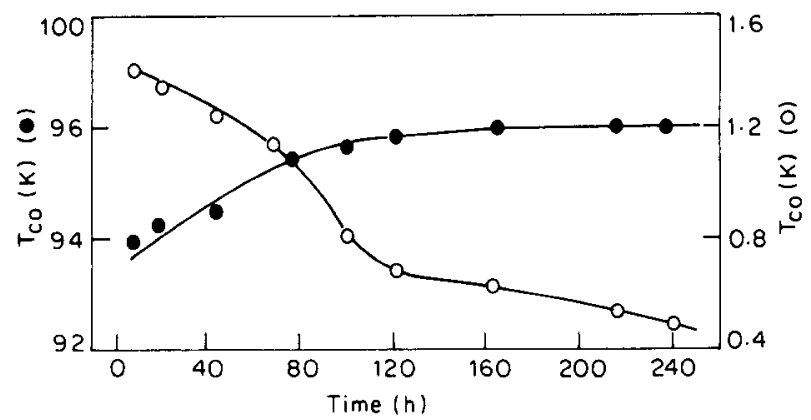

Figure 6. Characteristics of the transition into the superconducting state vs time of heat treatment. 
Additional heating of hot-pressed ceramics at $850940 \mathrm{C}$ allows elimination of oxygen deficit on the surface (figure 4) to increase ceramic density (figure 5) and improve its superconducting properties (figure 6). The latter effect is probably connected with the concentration decrease of impurities located at grain boundaries and compensation of oxygen non-stoichiometry.

On the basis of these studies the preparation technique for $\mathrm{LnBa}_{2} \mathrm{Cu}_{3} \mathrm{O}_{7-y}$ (where $\mathrm{Ln}=\mathrm{La}, \mathrm{Y}, \mathrm{Yb}, \mathrm{Ho}, \mathrm{Er}, \mathrm{Eu}, \mathrm{Gd}, \mathrm{Dy}, \mathrm{Sm}, \mathrm{Tm}$ ) targets has been developed. The targets may be made in the form of disks $(10210 \mathrm{~mm}$ in diameter and $2-20 \mathrm{~mm}$ thick $)$ or cylinders (with outer and inner diameters of $15-20$ and $6-8 \mathrm{~mm}$ respectively and 10- $30 \mathrm{~mm}$ high).

$\mathrm{YBa}_{2} \mathrm{Cu}_{3} \mathrm{O}_{7-y}$ films obtained using these targets have the following characteristics: $T_{c}=90-92 \mathrm{~K}, \Delta T_{c} \sim 1.5-2 \mathrm{~K}, I_{c} \sim 3 \cdot 3 \times 10^{6} \AA / \mathrm{cm}^{2}$ at $77.4 \mathrm{~K}$.

A technology for manufacturing magnetic shields from the $\mathrm{YBa}_{2} \mathrm{Cu}_{3} \mathrm{O}_{7-v}$ powder by an isostatic compression has also been elaborated. Density of the shield material varied from 78 to $93^{\circ}{ }_{0}$ with respect to the theoretical value, depending on the particular conditions of pressing. Size of model samples of shields is as follows: outer diameter $1520 \mathrm{~mm}$, inner diameter $6-12 \mathrm{~mm}$ and well depth $40-60 \mathrm{~mm}$. The shielding coefficient, on lowering the temperature from 93 to $90 \mathrm{~K}$, varied from 1 to not less than $2 \times 10^{4}$ for the longitudinal external magnetic field. In the transverse magnetic field the shielding coefficient in the frequency range of $70-3000 \mathrm{~Hz}$ was not less than $10^{5}$ up to the field $H_{\mathrm{c} 1}=79$ Öe. Unfortunately the sensitivity of the measuring path prevented estimation of shielding coefficient with higher accuracy. The absence of frequency dependence of the shielding coefficient reveals that the true one is 1.2 orders higher.

\section{Conclusions}

A method has been worked out for the preparation of high-quality HTSC ceramics with 1-2-3 composition and which possesses high superconducting characteristics, structural and phase uniformity.

This method enables manufacture of various ceramic articles, including targets for magnetron and laser sputtering, their size reaching $210 \mathrm{~mm}$. Films obtained from these targets have $I_{c}$ of $3 \cdot 3 \times 10^{6} \mathrm{~A} / \mathrm{cm}^{2}(77 \mathrm{~K})$ with $T=90-92 \mathrm{~K}$ and $\Delta T_{\mathrm{c}}=1.5-2 \mathrm{~K}$. Shields prepared according to this method have a shielding coefficient of $10^{5}$ with $H_{c}=79 \ddot{O} \mathrm{e}$ in the constant magnetic field and in the alternating magnetic field the amplitude is 90 Öe in the frequency range of $70-3000 \mathrm{~Hz}$.

\section{References}

Antonova V V et al 1988 Study of the conditions for the preparation, composition and properties of dense superconducting ceramics $\mathrm{Y}-\mathrm{Ba}-\mathrm{Cu}-\mathrm{O}$, Preprint Inst. Metal-lofiziki Akad. Nauk UkrSSR. Kiev. $N$ IMF-13-88, p. 5

Blank A B, Zagoskin V T, Kvichko L A, Kotok LA, Litvinenko Yu G and Seminozhenko V P 1988 Physica $153-155$ pp. 1663

Seminozhenko V P et al 1988 Dokl. Akad. Nauk. Ukr.SSR, ser. A, p. 50

Zagoskin V T, Kuznetsov V P, Lakin E E, Litvinenko Yu G, Puzikov V M, Moghilko E T and Seminozhenko V P 198811 European Crystallogr. Meeting, Programme changes and late abstracts, Austria, p. 9 